\title{
Large Obstructed Epigastric Hernia: an Unusual Presentation
}

\author{
Dr. Partha Pratim Mandal ${ }^{1}$, Dr. Tanushree Mondal ${ }^{2}$ ' Dr .Syed Shahjahan Siraj ${ }^{3}$ \\ ${ }^{I}$ (Assistant Professor, Department of General Surgery, Malda Medical College, Malda, West Bengal, India) \\ ${ }_{2}^{2}$ (Assistant Director of Medical Education \& Assistant Professor, Department of Community Medicine, IPGME \\ $\&$ R, Kolkata, West Bengal, India) \\ ${ }_{3}^{3}$ Assistant Director of Health Services (NCD-I), Department of Health \& Family Welfare, Swasthya Bhawan, \\ West Bengal, India)
}

\begin{abstract}
Epigastric hernia is a rare form of ventral hernia. Obstructed epigastric hernia containing gut is very very rare presentation of usual epigastric hernia. We presented here a 72 years old man with an unusual presentation of very large voluminous mass in the anterior abdominal wall (epigastric hernia) of more than 30 years duration. Surgery revealed an epigastric hernia presenting as an inter-parietal hernia. The hernial sac contained omentum, transverse colon, part of stomach and the patient presented with acute obstruction. No similar case has been found in the medical literature.
\end{abstract}

Keywords: Epigastric, Interparietal hernia, obstruction, Omentum, transverse colon,

\section{Introduction}

A hernia is a protrusion of a viscus or part of a viscus through an abnormal opening into an abnormal situation with its coverings. ${ }^{1}$ Epigastric hernia is a rare form of ventral hernia and occurs through the linea alba anywhere between the xiphoid process and the umbilicus. It accounts for $0.4-1.5 \%$ of all abdominal wall hernias as clinical presentation and approximately 5\% general population at autopsy. It is usually seen in middle-aged

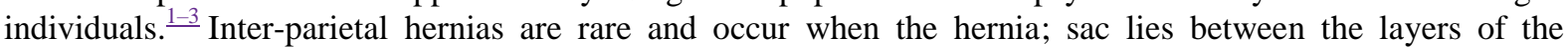
abdominal wall. We report a rare case of an obstructed epigastric hernia presenting as a giant ventral interparietal hernia containing omentum, transverse colon and part of stomach.

\section{Case Presentation}

A 72-year-old male farmer presented with tender mass in the upper abdomen of one week duration. It was associated with abdominal pain, nausea, vomiting in the last two days before admission. His condition started more than 30 years ago as a small mass in the upper abdomen that increased overtime to involve the upper central of the abdomen. During this long time it was painless and causing no symptoms except the enormous size of the mass made him uncomfortable. The patient was known case of COPD.

On examination, vital signs were normal (blood pressure $130 / 80 \mathrm{mmHg}$, pulse rate 80 beats/min, respiratory rate 22 cycles/min, and temperature $36.6{ }^{\circ} \mathrm{C}$ ), essential findings were abdominal (Fig. 1a and b): giant irregular mass extending from the epigastrium to the right hypochondrium measuring $32 \mathrm{~cm} \times 22 \mathrm{~cm} \times 8 \mathrm{~cm}$. The overlying skin appeared tense and red; the mass lesion was tender, firm and irreducible. There were no bowel sounds heard over the mass. Digital rectal examination was unremarkable. Heamogram showed $\mathrm{Hb} 11 \mathrm{gm} \%$, WBC $6.8 \times 10^{9} / 1$. ECG showed nonspecific ST depression and chest X-ray was suggestive of COPD. Abdominal ultrasound scan report revealed obstructed omentum \& intestine. MRI provided a pre-operative diagnosis of obstructive epigastric hernia containing omentum and also intestine.

\section{Findings}

Intra-operative findings were eventful (Fig. 2).Epigastric defect in the linea alba measuring $6 \mathrm{~cm} \times 5 \mathrm{~cm}$. Huge hernial sac protruding through the defect into the abdominal wall between the external oblique and the skin on the right extending to the flank. The sac contained large amount of omentum, part of transverse colon, part of greater curvature of stomach. There is partial obstruction of transverse colon. All the contents was adhered between the skin and the external oblique muscle/fascia. Adhesiolysis was by blunt and sharp dissection to free the hernia up to the neck. The sac was opened. The content was detached from the sac wall. Excess omentum was excised. Obstructed transverse colon was reduced. Stomach was reverted to its original position. The sac was transfixed at the neck and excised. Hernial repair was by simple suture with prolene no 01. The redundant skin was excised and closed over a drain. Postoperative period was uneventful and after that, the patient was discharged for outpatient review after 10 days. 


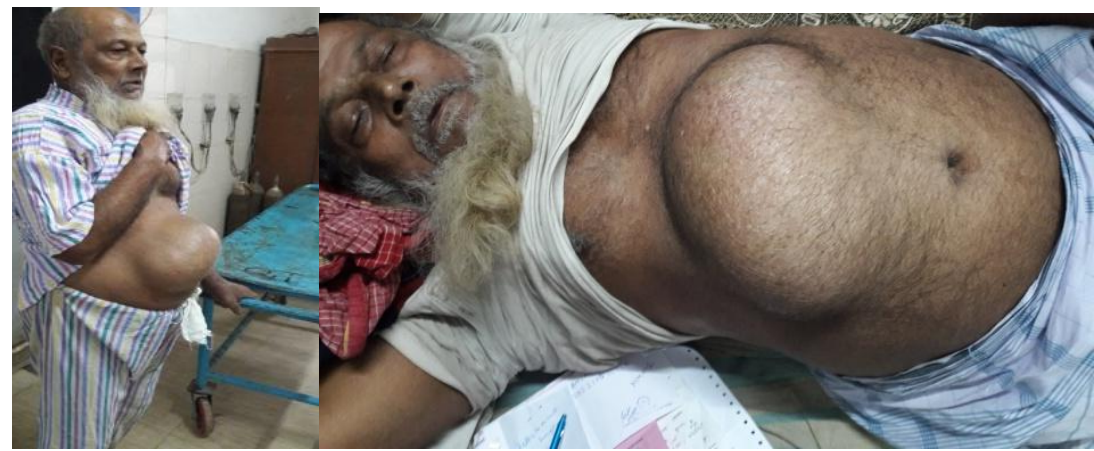

Fig. 1(a\&b) Clinical photograph of the obstructed epigastric hernia—standing and supine position.

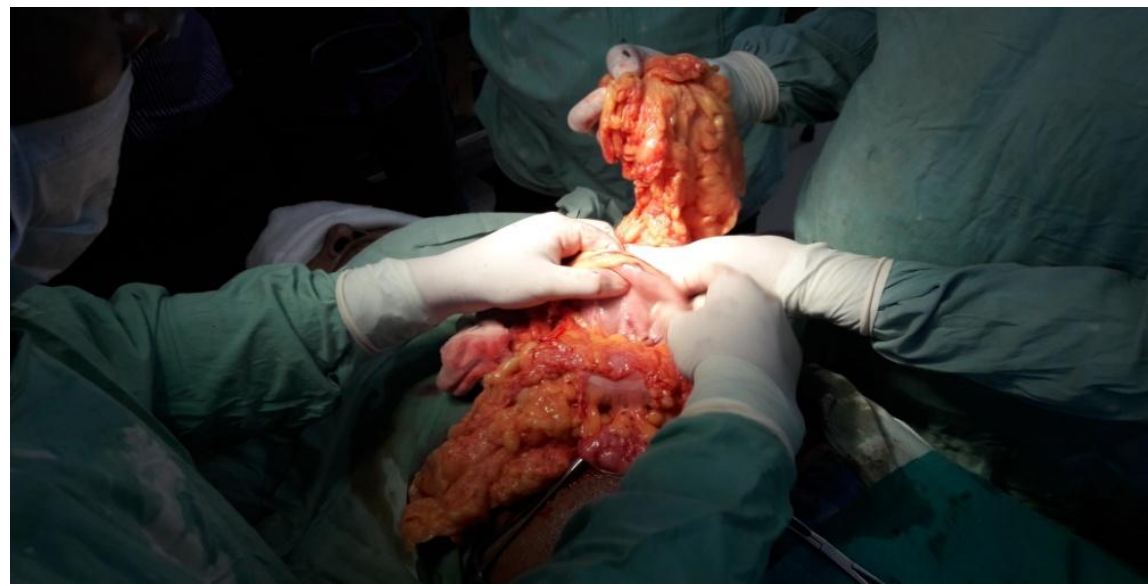

Fig. 2 Clinical photograph showing epigastric hernia sac containing omentum, part of transverse colone, part of greater curvature of stomach.

\section{DISCUSSION}

Hernias are common presentation in Sub-Asian region; however, the true incidence is unknown. It is estimated that $5 \%$ of the population will develop an abdominal wall hernia but the prevalence even may be higher. ${ }^{2.4}$ Epigastric hernia is a rare form of ventral abdominal hernia and accounts for $0.4-1.5 \%$ of all abdominal hernias. ${ }^{\underline{3}}$

An Epigastric hernia occurs through the linea alba anywhere between the xiphoid process and umbilicus. It may present as a small mass rarely large enough to admit more than a small amount of extra peritoneal fat or may be voluminous as was our case. It may contain epiploic appendages or viscera (ileum loops, stomach). ${ }^{-5}$ Palade et al. reported strangulated epigastric hernia with transverse colon necrosis. ${ }^{6}$ Arowolo et al. reported epigastric hernia with acute gastric outlet obstruction. Epigastric hernia may present with an empty sac, extra peritoneal fat or it contains intra peritoneal organs, ${ }^{1}$ as found in our patient.

We report our experience with a giant or voluminous irreducible epigastric hernia with a $6 \mathrm{~cm} \times 5 \mathrm{~cm}$ defect in the linea alba (Fig. 2). The huge hernial sac contained large amount of omentum, part of transverse colon, part of greater curvature of stomach. There was obstruction of transverse colon. All the contents were adhered between the skin and the external oblique muscle/fascia. The patient presented with acute features. No structures were gangrenous.

Bartolin first described interparietal hernia in 1661 and its definition has not changed. It is rare and has a hernial sac that passes between layers of the anterior abdominal wall. ${ }^{1.4}$ However, 3 (Three) subtypes have been described recently, preperitoneal (between peritoneum and transversalis fascia), interstitial (between transversalis fascia and transversalis, internal or external oblique muscles) and superficial (between external oblique and skin). ${ }^{?}$ Our index patient presented with the superficial type.

The correct preoperative diagnosis can be difficult with the diagnosis usually determined during operation. ${ }^{4.8}$ This concurs with our experience. We have not come across any report in the literature of epigastric hernia presenting as obstructed epigastric hernia. Most obstructed hernias reported have been inguinal. $\frac{8,9}{9}$

Surgical correction is the only treatment of epigastric hernia and does not always need prosthesis repair. However, prosthesis is useful in voluminous hernias with wide neck. ${ }^{-5}$ Though our patient presented with a voluminous hernia, repair was done by primary reconstruction. Despite the dimension of the hernia, the choice of repair depends on the hernial defect and patient's presentation. 


\section{Conclusion}

We present this case as we have failed to find any previous reported case in the medical literature and conclude that an intra peritoneal epigastric hernia can attain voluminous dimension and present with features of obstruction.

\section{References}

[1] Mark A. Malangoni, MD Michael J. Rosen, MD; Townsend: Sabiston Textbook of Surgery, 18th ed. CHAPTER 44 - Hernias

[2] Badoe E.A., Archampong E.Q., da Rocha-Afodu J.T. Principles and Practice of Surgery. 3rd ed. Ghana Publishing Corporation; Accra, Ghana: 2000. Hernia. p. 482-502.

[3] Arowolo O.A., Ogundiran T.O., Adebamowo C.A. Spontaneous epigastric hernia causing gastric outlet obstruction: a case report. Afr J Med Sci. 2006;35(3):385-386. [PubMed]

[4] Malangoni M.A., Gagliardi R.J. Hernias. In: Townsend C.M., Beauchamp R.D., Evers B.M., Mattox K.L., editors. Sabiston textbook of surgery. 17th ed. Saunders; Philadelphia: 2004

[5] Corsale I., Palladino E. Diagnosis and treatment of epigastric hernia. Analysis of our experience. Mierva Chir. 2000;55(9):607610. [PubMed]

[6] Palade R., Voiculescu D., Suliman E. Voluminous complicated epigastric hernia. Chirurgia (Bucur)2009;104(3):337-340. [PubMed]

[7] Maingot's Abdominal Operations > Chapter 5. Hernias

[8] Zollinger RM Jnr. Classification of ventral and groin hernias. In Fitzgibbons RJ, Greenburg AG (editors). Nyhus and condons hernia. Philadelphia: Lippincott Williams and Wilkins; 2002. p. 71-9.

[9] Mulholland, Michael W.; Lillemoe, Keith D.; Doherty, Gerard M.; Maier, Ronald V.; Upchurch, Gilbert R. Title: Greenfield's Surgery: SCIENTIFIC PRINCIPLES AND PRACTICE, 4th Edition 